PRODUCTION

ENGINEERING ARCHIVES
2016, Vol. 10, No 1, pp 2-4

ISSN 2353-5156

ISSN 2353-7779 (print version)

(online version)

Article history: $\quad$ Received: 04.01.2016

\title{
Use of statistical acceptance of products in the automotive industry
}

\author{
Agata Dudek ${ }^{1}$ \\ ${ }^{1}$ Czestochowa University of Technology, Institute for Material Engineering, Faculty of Production Engineering and Materials Technology, \\ Czestochowa, Dabrowskiego 69, Poland, phone 48343250721, dudek@wip.pcz.pl
}

\begin{abstract}
The article presents the results of studies on the implementation of statistical acceptance of products with the example of a styrene-rubber plastic connector, while considering particular stages of production. The characterization of factors determining the transition from normal inspection to relaxed or tightened inspection for products made of styrene-rubber plastic materials has been made. The effect of the type of inspection on the level of non-conformance of products has been determined.
\end{abstract}

Key words quality, SCP, automotive, control

\section{Rules of the statistical acceptance of styrene-rubber plastic connector}

The principles of the statistical inspection of a styrene-rubber plastic connector have been developed and implemented on the basis of the PN-ISO 2859+AC1 standards. Sampling plans based on the acceptable quality level (AQL) were used during lot-by-lot inspection [PN-ISO 2859-1:2003]. The following two inspection systems have been implemented in the enterprise:

- normal inspection (recommended as initial inspection); and

- tightened inspection -in situations of enhanced requirements or the necessity of tightening the inspection for other reasons.

These activities are applicable to the evaluation of connectors transferred between particular phases of production (UlewicZ R. 2003, ŠURINOVÁ Y.,
LeSTYÁNSZKA ŠKŮRKOvÁ K. 2013, SoŃTA G., DudEK A., SELEJDAK J., UlEWICZ R. 2015).

For the assessment of the quality of transportable lots with normal inspection, a single-stage sampling plan, the general inspection level II, and the acceptable quality level, $\mathrm{AQL}=2.5 \%$, were taken. A schematic diagram of the procedure is shown in Fig. 1.

In order to determine the conformance of a transportable lot to the specification, it is necessary to:

- establish the number of pieces in the transportable lot,

- take a random sample of products of the size as specified in the sampling plan,

- examine each piece taken for conformance with the established acceptance criteria and determine whether it is good or bad, then count bad pieces in the sample and compare their number with the qualifying and disqualifying numbers - isolate the rejects and mark them with the card "Rejects"; 
- consider the lot as conforming to the requirements, if the number of bad pieces in the sample is equal or less than the qualifying number;

- consider the lot as non-conforming to the requirements, if the number of bad pieces in the sample is equal or greater than the qualifying number;

- consider the lot as non-conforming to the requirements, if the number of bad pieces in the sample is equal or greater than the qualifying number, and mark it with the card "To be sorted / reworked".

The procedure for the assessment of a transportable lot with tightened inspection is similar to that for normal inspection, except for the number of acceptable nonconformities in the sample, which is different. Figure 1 shows the schematic diagram of the statistical control procedure.

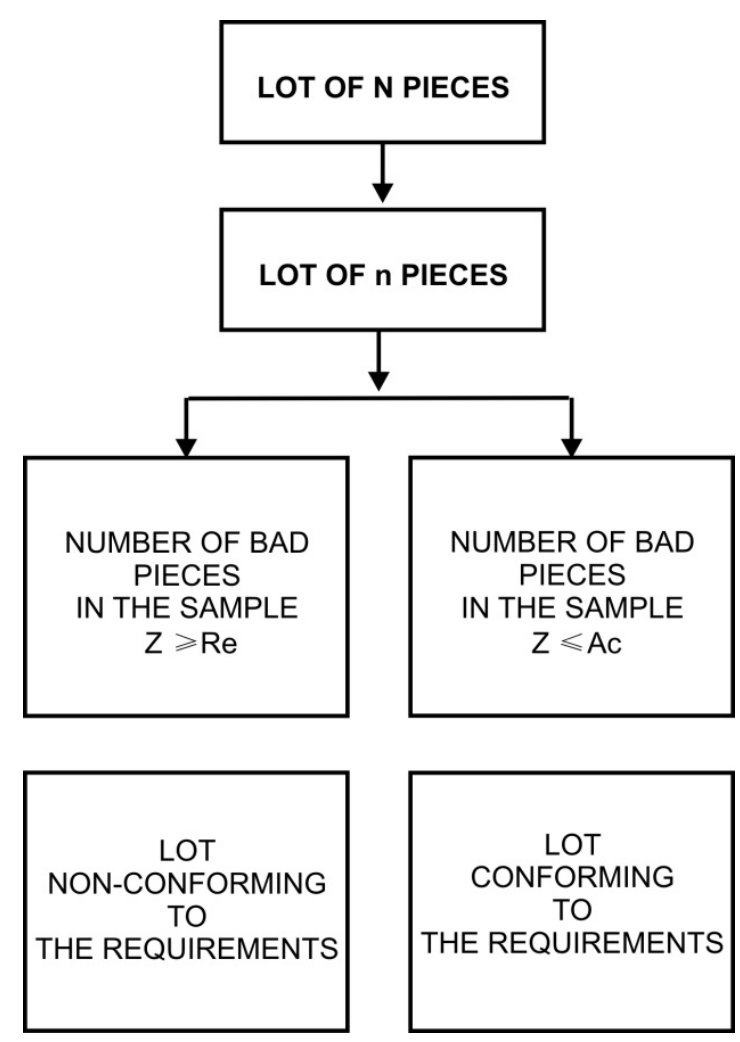

Fig. 1. Schematic diagram of the statistical control procedure: Ac-qualifying number, Re-disqualifying number, $N$ - lot size, $n$ - sample size, $Z$ - number of bad pieces found in the sample.

Source: own study

\section{Conditions and procedures of transition}

- Transition from normal inspection to tightened inspection. When performing normal inspection, tightened inspection should be introduced, when two of five or less successive lots are found to be non-conforming to the requirements at the first time during inspection, which means that lots resubmitted are not taken into account in this procedure.

- Transition from tightened inspection to normal inspection. When performing tightened inspection, normal inspection should be restored, if five successive lots have been considered conforming to the requirements at the first time during inspection.

- Transition from normal inspection to relaxed inspection. When performing normal inspection, relaxed inspection should be introduced, if all of the following conditions are satisfied:

o 10 previous lots were submitted to normal inspection and all of them were accepted at the first time during inspection,

o the total number of non-conforming units in the samples taken from the 10 previous lots is equal or less than the applicable limiting number,

o production is stable,

0 relaxed inspection has been recognized as advisable by the authorized person.

- Transition from relaxed inspection to normal inspection. When performing relaxed inspection, normal inspection should be restored, if any of the following conditions occurs for the first time during inspection:

o the lot has not be accepted,

o the lot has been considered acceptable on the basis of the relaxed inspection procedures,

o deliveries have become irregular or delayed,

o other conditions exists, which justify the necessity of restoring normal inspection.

Figure 2 shows a schematic diagram of conditions for transition from normal inspection to relaxed or tightened inspection. 


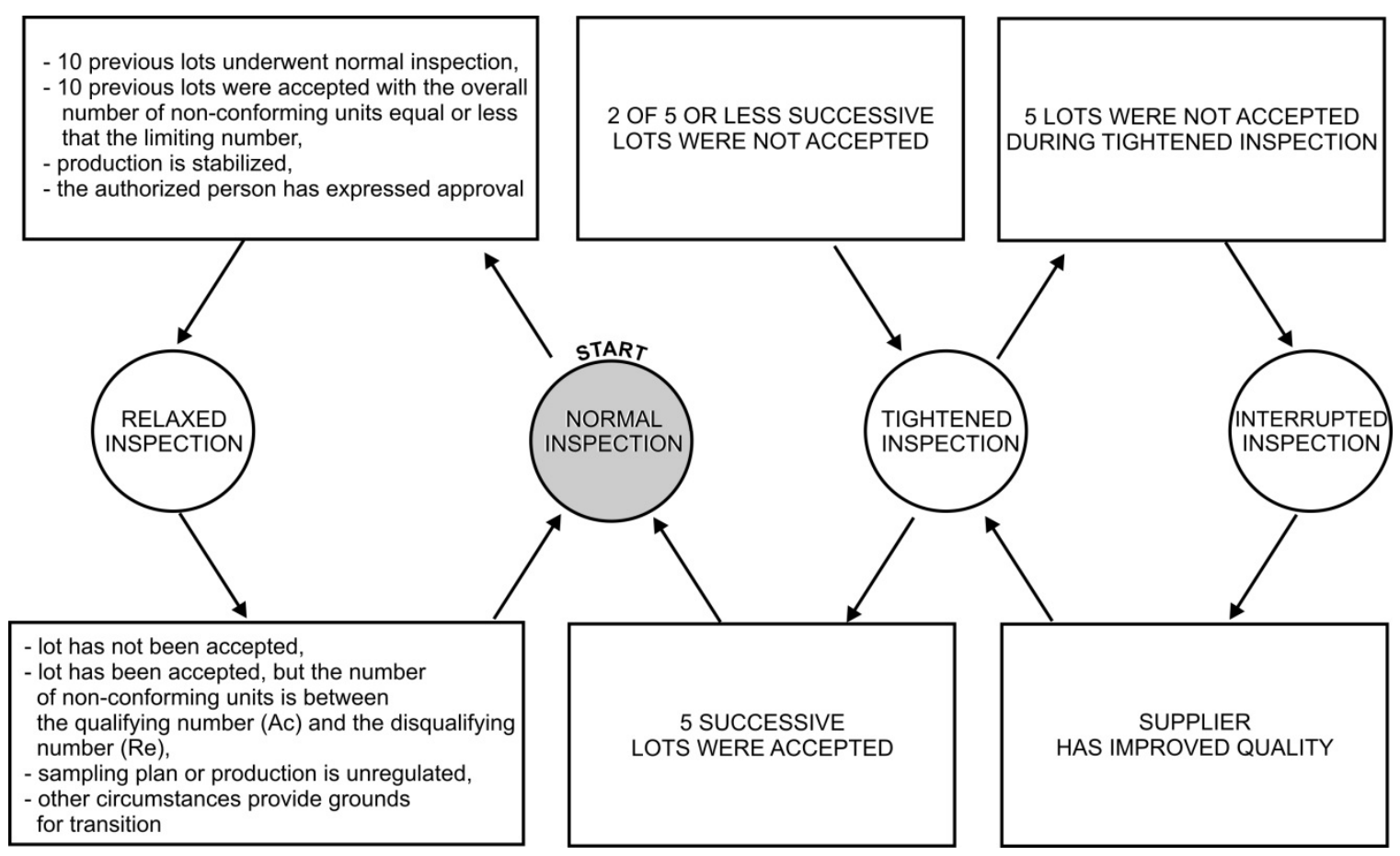

Fig. 2. Schematic diagram of transition from normal inspection to relaxed and tightened inspections.

Source: own study

\section{Conclusion}

The development and implementation of the statistical acceptance of styrene-rubber plastic connectors for serial manufacturing on particular stages of production have brought about a reduction of non-conforming products and faulty products by $9 \%$. Data coming from inter-operational acceptance are processed by the Quality Control Department and the Production Planning Department. The results of analyses serve for modifying the parameters of the production cycle. By using processed statistical data, new procedures for taking actions at the limiting number of nonconformities have been developed. This has enabled the shortening of time necessary for the identification of the critical points of the production cycle. The large number of factors influencing the quality of produced styrene-rubber plastic connectors requires careful quality control. The use of a variable quality inspection system is quite expensive and is associated with the necessity of engaging larger human and equipment resources. The

mechanism of transition from normal inspection to tightened or relaxed inspection requires an immediate change of inspectional and executive procedures [Ulewicz R., Dima I.C., Grabara J. 2013]. The implementation of this form of inspection has proved to be more efficient that the traditional form of quality control, and, in combination with new procedures, shortened the time from the identification of a nonconformance to the initiation of corrective actions.

\section{References}

1. ISO 2859-1:2003

2. ŠURINOVÁ Y., LESTYÁNSZKA ŠKŮRKOVÁ K. 2013 Brief Review Of German Standards For Quality Audits In Automotive Production, Production Enginerring Archves Vol.1, pp. 35-37.

3. SOŃTA G., DUDEK A., SELEJDAK J., ULEWICZ R. 2015 Analysis of structure of elements for automotive industry, Applied Mechanics and Materials, Vol. 712, pp. 81-86

4. ULEWICZ R. 2003, Quality control system in production of the castings from spheroid cast iron, Metalurgija, Vol. 42, Issue 1, pp. 61-63

5. Ulewicz R., Dima I.C., Grabara J. 2013, Quality Assurance in the Process of Material Selection and Production of Semitrailer Structure Parts. Metalurgia International, Vol.18 no 7, pp. 195-199 